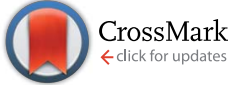

Cite this: Chem. Sci., 2015, 6, 964

\title{
Combining luminescence spectroscopy, parallel factor analysis and quantum chemistry to reveal metal speciation - a case study of uranyl(vi) hydrolysis $\uparrow$
}

\author{
Björn Drobot, ${ }^{\text {a }}$ Robin Steudtner, ${ }^{a}$ Johannes Raff, ${ }^{\text {ab }}$ Gerhard Geipel, $^{a}$ \\ Vinzenz Brendler ${ }^{a}$ and Satoru Tsushima*a
}

This study of aqueous metal speciation is an advanced combination of theoretical and experimental methods. Continuous wave (CW) and time-resolved laser-induced fluorescence spectroscopy (TRLFS) data of uranyl(VI) hydrolysis were analyzed using parallel factor analysis (PARAFAC). Distribution patterns of five major species were thereby derived under a fixed uranyl concentration $\left(10^{-5} \mathrm{M}\right)$ over a wide $\mathrm{pH}$ range from 2 to 11 . UV (180 $\mathrm{nm}$ to $370 \mathrm{~nm}$ ) excitation spectra were extracted for individual species. Time-dependent density functional theory (TD-DFT) calculations revealed ligand excitation (water, hydroxo, oxo) in this region and ligand-to-metal charge transfer (LMCT) responsible for luminescence. Thus excitation in the UV region is extreme ligand sensitive and specific. Combining findings from PARAFAC and DFT the $\left[\mathrm{UO}_{2}\left(\mathrm{H}_{2} \mathrm{O}\right)_{5}\right]^{2+}$ cation (aquo complex $\left.1: 0\right)$ and four hydroxo complexes $(1: 1$, $3: 5,3: 7$ and $1: 3)$ were identified. The methodological concept used here is applicable to luminescent metals in general and thus enables acquisition of refined structural and thermodynamical data of lanthanide and actinide complexation.

Received 8th July 2014

Accepted 24th October 2014

DOI: $10.1039 / \mathrm{c} 4 \mathrm{sc} 02022 \mathrm{~g}$

www.rsc.org/chemicalscience

\section{Introduction}

The environmental impact of metals depends on their concentration and more importantly their speciation. A broad variety of methods can be applied to determine speciation, e.g. separation by ion exchange, ${ }^{1}$ solvent extraction methods, ${ }^{2,3}$ as well as diffusive gradients in thin films. ${ }^{4}$ Enthalpic data $\left(\Delta_{\mathrm{r}} S\right.$, $\Delta_{\mathrm{r}} H$ and $\left.\Delta_{\mathrm{r}} C_{\mathrm{p}}\right)$ is often derived from either potentiometric ${ }^{5}$ or calorimetric $^{6}$ titrations. However, it is far from trivial to derive a unique set of chemical species with correct stoichiometries and structure from such experiments. Most often a couple of sensible species sets are tested against the experimental results. Then the model yielding the smallest overall deviation between fitted and real values ( $\chi^{2}$ minimization) is considered to be the best. In contrast, techniques such as ESI-TOF provide direct stoichiometric information but no thermodynamic data. ${ }^{7,8}$ Whereas both thermodynamic and structural parameters can be obtained from luminescence spectroscopy, a correlation of

${ }^{a}$ Helmholtz Zentrum Dresden Rossendorf, Institute of Resource Ecology, Bautzner Landstraße 400,01328 Dresden, Germany.E-mail: b.drobot@hzdr.de; s.tsushima@ $h z d r . d e$

${ }^{b}$ Helmholtz Zentrum Dresden Rossendorf, Helmholtz Institute Freiberg for Resource Technology, Halsbrücker Straße 34, 09599 Freiberg, Germany

$\dagger$ Electronic supplementary information (ESI) available: Calculated excitation spectra (including $2: 2$ complex) and atomic coordinates used for TD-DFT. See DOI: $10.1039 / \mathrm{c} 4 \mathrm{sc} 02022 \mathrm{~g}$ spectral shape and structure is usually not possible. Increased computational power makes quantum chemical calculations a helpful complementary method. Spectral features thus obtained can be correlated to structural information. This work intends to exploit current capabilities of state-of-the-art combinations of spectroscopy, quantum chemistry, and data processing.

Uranyl(vi) hydrolysis is selected as an ideal system for a proof of concept. It is the elementary uranium aqueous ligand system and constitutes the basis for all more complex natural systems. The formation of oligomeric complexes makes uranyl(vi) hydrolysis one of the most diverse systems in aqueous heavy metal chemistry. Although uranyl(vi) speciation has been studied for decades a clear determination and complete understanding is still missing. The current general conception is represented by the updated thermochemical database (TDB) of the Nuclear Energy Agency (NEA). ${ }^{9}$ Recent studies prove there are still some open questions especially about polynuclear species. ${ }^{6,10}$

The major part of thermodynamic uranyl(vi) data is based on potentiometric or calorimetric titrations. ${ }^{11-13}$ For the acidic as well as for the alkaline $\mathrm{pH}$ range complementary spectroscopic methods like IR, ${ }^{14}$ EXAFS, ${ }^{15,16}$ Raman $^{17}$ and NMR ${ }^{18}$ are applicable. For all of them relatively high concentrations up to several millimolar are required. This limits the use of these methods because of low uranyl(vi) solubility in the circumneutral $\mathrm{pH}$ range. 
Luminescence spectroscopic methods with their high sensitivity offer a solution for this problem. The detection limit depends on the experimental setup and quantum yield of the complexes and can reach the nanomolar level. Since luminescence spectra lack direct structural information their assignment to complexes is mainly based on comparison with a thermodynamic database.

Discrimination of several components in a single fluorescence signal is a challenging problem. In previous works, time as an additional dimension was used for uranyl(vi) spectra deconvolution. ${ }^{19-22}$ But due to the lack of unique analysis methods and different experimental setups results of deconvolution are often not consistent. Site selective excitation is another method to discriminate between luminescence spectra of individual species. It was successfully applied to $\mathrm{Cm}$ (III) and Eu(III) cryo spectroscopy. ${ }^{23,24}$ However, inhomogeneous broadening leads to a smearing of excitation spectra at room temperature and interpretation becomes difficult.

In this study an advanced combination of luminescence spectroscopic and theoretical methods is proposed and evaluated to get new insights into uranyl(vi) hydrolysis. Time-resolved laser-induced fluorescence spectroscopy (TRLFS) and continuous wave (CW) spectroscopic data are recorded for a wide $\mathrm{pH}$ range. Parallel factor analysis (PARAFAC), ${ }^{25,26}$ a generalization of two-dimensional principal component analysis (PCA) to higher orders, was used to extract detailed and consistent speciation information from spectroscopic data. Electronic absorption spectra were calculated using time-dependent density functional theory (TD-DFT). Comparison of theory and experiment provided spectra-to-complex correlation and also identification of the excitation origin in the UV region.

\section{Theory}

\section{Parallel factor analysis (PARAFAC)}

This method was developed as a robust analysis for a direct determination of unique explanatory factors. In this study explanatory factors correspond to chemical species. Anderson and Bro have shown that simultaneous analysis of multi-way data with three or more independent variables measured in a crossed fashion overcomes the rotation problem and a unique solution of such a model could be found ${ }^{27}$ It was demonstrated that PARAFAC is a useful tool for selective excitation luminescence spectroscopy ${ }^{28,29}$ as well as for TRLFS data. ${ }^{30}$

In the following section PARAFAC is illustrated using the example of TRLFS. Raw data were baseline corrected and normalized to a luminescence maximum of one before analysis to ensure equal weighting. Afterwards 2D data (emission wavelength versus time) from measurements at different $\mathrm{pH}$ values were stacked to a $3 \mathrm{D}$ data cube (Fig. 1, top). This data cube is a linear combination of individual cubes for respective chemical species ( 1 to $f$ ) and additional noise (Fig. 1, middle, adapted from Bro et $a l .{ }^{31}$ ). Deconvolution with PARAFAC results in three matrices $(\mathrm{A}-\mathrm{C})$. The number of matrix columns equals the number of chemical species and the $i$-th column of each matrix represents the $i$-th species (Fig. 1, bottom). Therefore the fraction of the $i$-th chemical species within the data is explained by the vectors $a_{i}, b_{i}$ and $c_{i}$. Each of the matrices contains

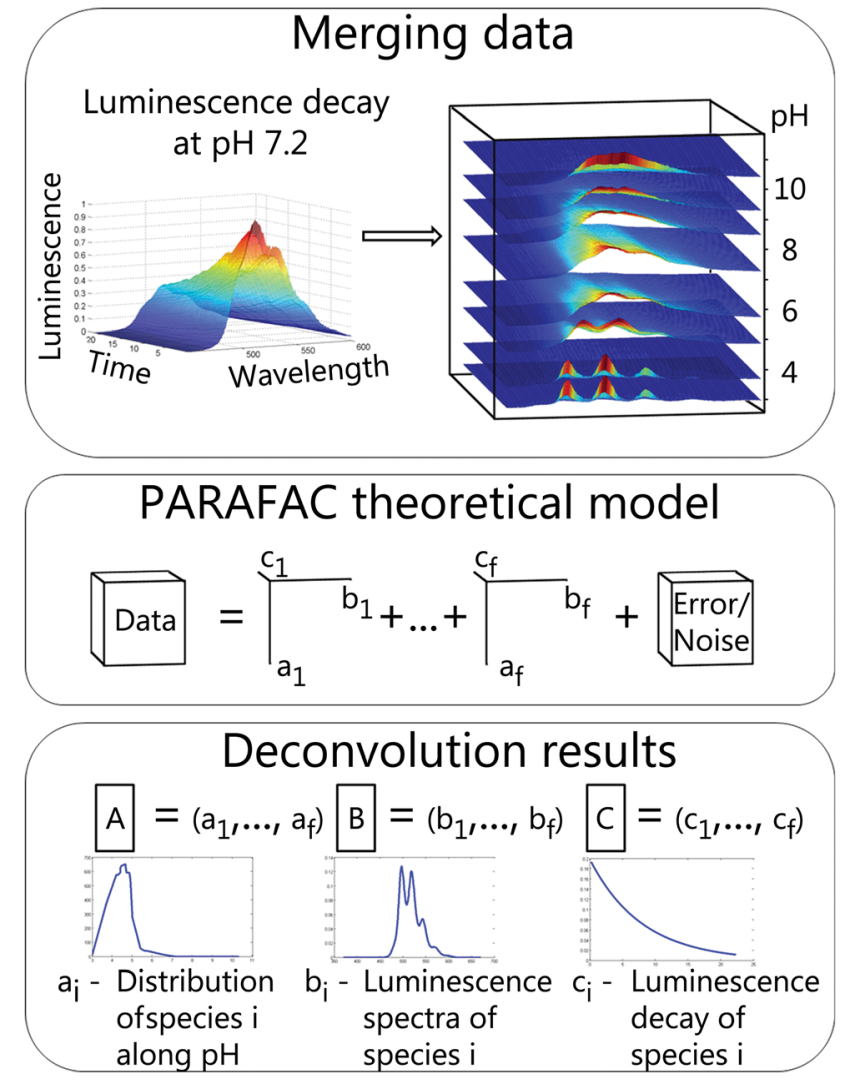

Fig. 1 PARAFAC with TRLFS data. Top: merging data: background corrected data matrices for individual $\mathrm{pH}$ values stacked to a data cube. Middle: PARAFAC theoretical model: scheme with 3 independent variables $(\mathrm{pH}$, wavelength and time) and $f$ factors (chemical species). Bottom: deconvolution results: each of the three output matrices $(A-C)$ contains parameter specific vectors for determined species: species distribution (A), luminescence spectra (B), luminescence decays (C).

intrinsic characteristics of chemical species along particular parameters (here $\mathrm{pH}$, emission wavelength, and time) providing direct access to species distribution, luminescence spectra and luminescence decays.

PARAFAC has already been implemented as the $\mathrm{N}$-way Toolbox $^{27}$ for the MATLAB software. Toolbox details can be found in literature ${ }^{31-33}$ and an excellent online tutorial is accessible. ${ }^{34}$ In this study PARAFAC was used for modelling uranyl(vI) hydrolysis data from TRLFS and CW spectroscopy and thus, chemical species correlate with uranyl(vi) complexes.

Unimodal (one maximum for speciation) and nonnegative (for luminescence spectra) constraints were used for the model as already implemented in the $\mathrm{N}$-way Toolbox $3.31 .{ }^{27}$ Based on the Optimization Toolbox a monoexponential constraint for the fluorescence decay was additionally implemented. Spectra and lifetimes were normalized directly by the PARAFAC algorithm. All Toolboxes were used with Matlab R2013a.

\section{Quantum-chemical calculations}

Calculations were performed in an aqueous phase using the Gaussian 09 program ${ }^{35}$ employing the density functional theory 
(DFT) by using a conductor like polarizable continuum model. ${ }^{36,37}$ Structure optimizations were performed for $\left[\mathrm{UO}_{2}\left(\mathrm{H}_{2} \mathrm{O}\right)_{5}\right]^{2+} \quad$ (aquo, $\left.1: 0\right), \quad\left[\mathrm{UO}_{2}(\mathrm{OH})\left(\mathrm{H}_{2} \mathrm{O}\right)_{4}\right]^{+} \quad(1: 1)$, $\left[\left(\mathrm{UO}_{2}\right)_{2}\left(\mu_{2}-\mathrm{OH}\right)_{2}\left(\mathrm{H}_{2} \mathrm{O}\right)_{6}\right]^{2+}(2: 2)$, and $\left[\left(\mathrm{UO}_{2}\right)_{3}\left(\mu_{3}-\mathrm{O}\right)\left(\mu_{2}-\mathrm{OH}\right)_{3}\left(\mathrm{H}_{2} \mathrm{O}\right)_{6}\right]^{+}$ (3:5) at B3LYP level $^{38,39}$ followed by vibrational frequency analysis at the same level to confirm the absence of imaginary frequencies. For the calculations of the electronic absorption spectra, nonequilibrium time-dependent DFT (TD-DFT) calculations ${ }^{\mathbf{4 0 , 4 1}}$ were applied in the aqueous phase producing only singlet excited states. One hundred (aquo and $1: 1$ ) and two hundred $(2: 2$ and $3: 5)$ singlet excited states were determined using the ground states geometries of each uranyl(vi) complex. For the absorption spectra, the half-width at half-height was defined as $0.2 \mathrm{eV}$. The energy-consistent small-core effective core potential and the corresponding basis set suggested by Küchle et $a l .{ }^{42}$ were used for uranium. The most diffuse basis functions on uranium with the exponent 0.005 (all s, p, d, and $\mathrm{f}$ type functions) were omitted as in previous studies. ${ }^{\mathbf{4 3 4}}$ For oxygen and hydrogen, the valence triple- $\zeta$ plus polarization basis was used. ${ }^{45}$ The spin-orbit effects and basis set superposition error corrections were neglected. Coordinates of all complexes are given in the ESI. $\dagger$

\section{Material and experimental}

\section{Material}

Sample preparation was carried out in an inert gas glove box (nitrogen) to avoid carbonate complexation. Uranyl(vi) solutions $\left(10^{-5} \mathrm{M} \mathrm{U}(\mathrm{vI})\right.$ in $10^{-2} \mathrm{M} \mathrm{NaClO}_{4}$ (Merck), unless stated otherwise) were prepared directly before the experiment. Same solutions without uranyl(vi) were used as blank. No precipitation was visually observed during the measurements. Pure water was degassed with nitrogen and stored in a glove box. Uranyl(vi) stock solution $\left(10^{-1} \mathrm{M}\right.$ in $\left.0.1 \mathrm{M} \mathrm{HClO}_{4}\right)$ was prepared from solid $\mathrm{UO}_{2}\left(\mathrm{NO}_{3}\right)_{2} \cdot 6 \mathrm{H}_{2} \mathrm{O}$ (Chemapol) as previously described. ${ }^{46} \mathrm{NaClO}_{4}$ solution was prepared before each experimental series. The sample $\mathrm{pH}$ ranged from 2 to 11 and was adjusted by adding suitable amounts of $\mathrm{NaOH}$ and $\mathrm{HClO}_{4}$ (Merck). The $\mathrm{pH}$ was measured directly after the luminescence measurements, to avoid quenching by chloride from the electrode. The $\mathrm{pH}$ measurements were carried out with a glass electrode (SenTix Mic, WTW), which was calibrated with 3 buffer solutions (NIST/ PTB standard buffers).

\section{Time-resolved laser-induced fluorescence spectroscopy (TRLFS)}

A quadrupled (266 nm) Nd:YAG laser (minilite, Continuum) with $0.3 \mathrm{~mJ}$ per $4 \mathrm{~ns}$ pulse was used for excitation of the sample in a quartz glass cuvette. A light guide was used for transmission of emitted light to the spectrometer (Horiba, slit width $200 \mu \mathrm{m})$. A 100 lines per $\mathrm{mm}$ grate produced monochromatic light (resolution circa $0.5 \mathrm{~nm}$ ) that was detected by a cooled $\left(-20{ }^{\circ} \mathrm{C}\right)$ ICCD camera (Horiba). The initial delay was set to 0.1 $\mu \mathrm{s}$ and an aperture of $4 \mu \mathrm{s}$ was used. An average of 75 accumulations was collected and the baseline correction was performed with the software LabSpec 5 (Horiba). A 150 ns step size for 148 spectra (setup $25^{\circ} \mathrm{C}$ ) and a $70 \mathrm{~ns}$ step size for 101 spectra (setup $1{ }^{\circ} \mathrm{C}$ ) were used, respectively. Sample temperature was fixed with a controlled Peltier element (TC125 Temperature Control, Quantum Northwest).

\section{Continuous wave (CW) spectroscopy}

Photoluminescence measurements were performed on a fluorescence spectrofluorometer (QuantaMaster 40) equipped with a $75 \mathrm{~W}$ xenon arc lamp. Wavelengths were chosen by motorized excitation and emission monochromators with a bandwidth of $10 \mathrm{~nm}$ and $2 \mathrm{~nm}$, respectively. Spectra were recorded by scanning emission with $1 \mathrm{~nm}$ resolution at each excitation wavelength. This procedure was iterated for the entire excitation range with $5 \mathrm{~nm}$ resolution. An integration time of $1 \mathrm{~s}$ was chosen. Sample temperature was fixed with a controlled Peltier element (identical to the previous). Data from CW spectroscopy were baseline corrected with the recorded blanks.

\section{Results and discussion}

Three independent series of luminescence spectroscopic experiments were performed. TRLFS experiments were run at $25{ }^{\circ} \mathrm{C}$, making them comparable to literature (see Table 1). For two additional series (TRLFS and CW spectroscopy) a temperature of $1^{\circ} \mathrm{C}$ was chosen where the quantum yield of the uranyl(vi) aquo ion is 3.8 times higher compared to $20{ }^{\circ} \mathrm{C}$ (see Fig. 2).

Results from all three experimental series are compared with the thermodynamic speciation. Speciation calculation for $25{ }^{\circ} \mathrm{C}$ was performed with the EQ3/6 package ${ }^{47}$ using the most updated thermodynamic data from NEA TDB. ${ }^{9}$

Data matrices for distinct $\mathrm{pH}$ values were collected individually for each experimental setup. Deconvolution according to Fig. 1 (section Experimental) results in the output of three matrices (A-C) for each experimental series. Five complexes were found to consistently explain the models. Explained variance $(>99 \%)$ as well as the core consistency diagnostics $(>60 \%)^{32}$ support the five complexes model.

The columns of matrices A correlate with the luminescence distribution along the pH scale (Fig. 3). Since PARAFAC yields only the distribution of complexes but no information on stoichiometry and structures, we assigned the complexes in a way that it reproduces best the computed thermodynamic speciation. At $\mathrm{pH}$ around 5 to 6 both $\mathrm{UO}_{2} \mathrm{OH}^{+}(1: 1)$ and $\left(\mathrm{UO}_{2}\right)_{2}(\mathrm{OH})_{2}{ }^{2+}$ $(2: 2)$ may prevail, according to the speciation calculation. However, only one complex was found and tentatively assigned to $1: 1$ (see below for a more detailed discussion).

The matrices B contain emission spectra of detected complexes. Spectra of different experiments (CW spectroscopy and TRLFS) were compared among themselves (Fig. 4) and found to be in good agreement. Each spectrum belongs to one complex in the $\mathrm{pH}$ distribution curves in Fig. 3. Thus the $\mathrm{pH}$ distributions combined with the shape of corresponding spectra clearly demonstrate the identity of extracted complexes within our three experiments.

The distribution patterns thus derived are very similar to those obtained from speciation modeling. Some minor 
Table 1 Luminescence spectroscopic parameters of uranyl(vi)-hydroxo complexes and comparison with literature. Main peaks are in bold

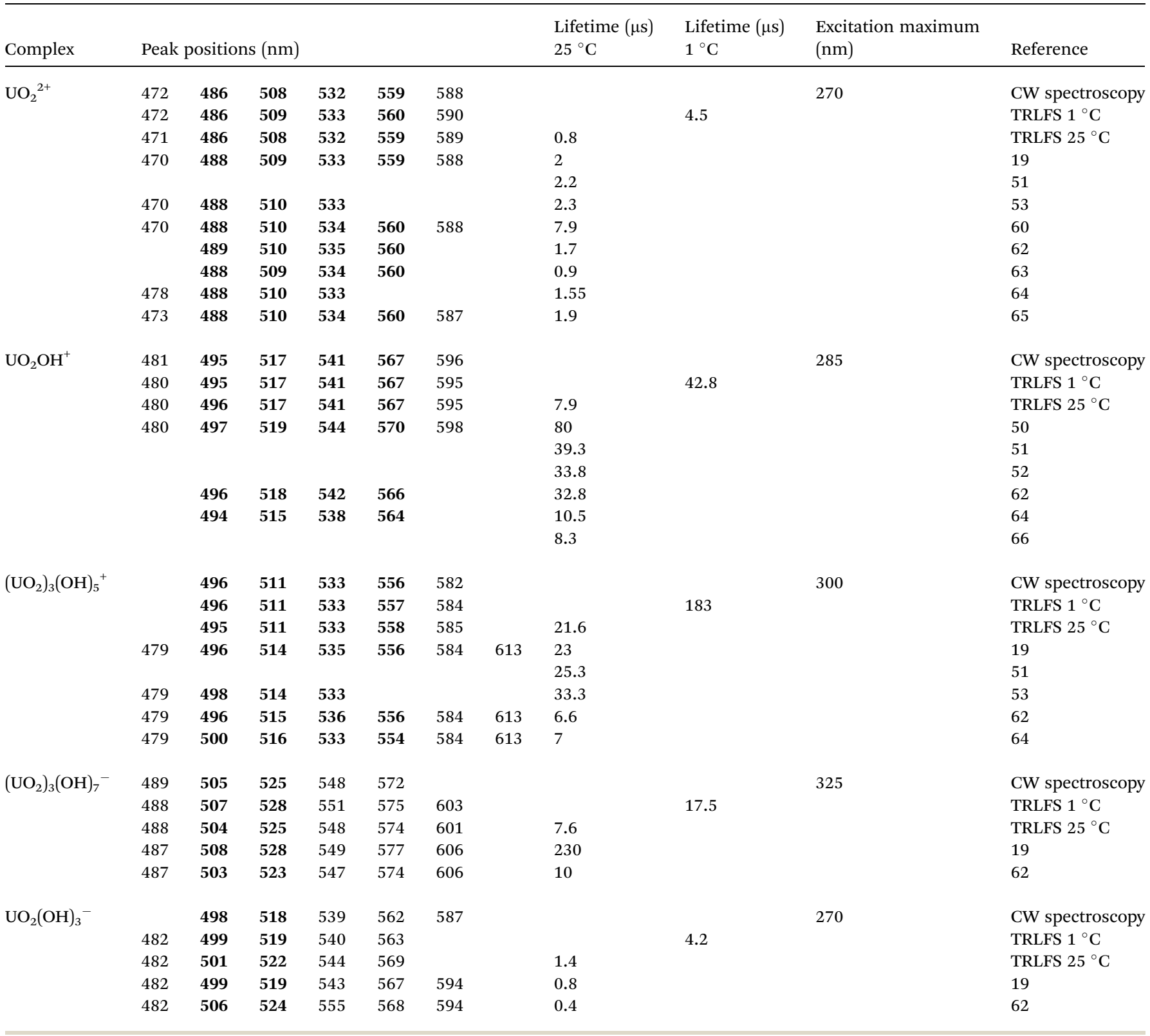

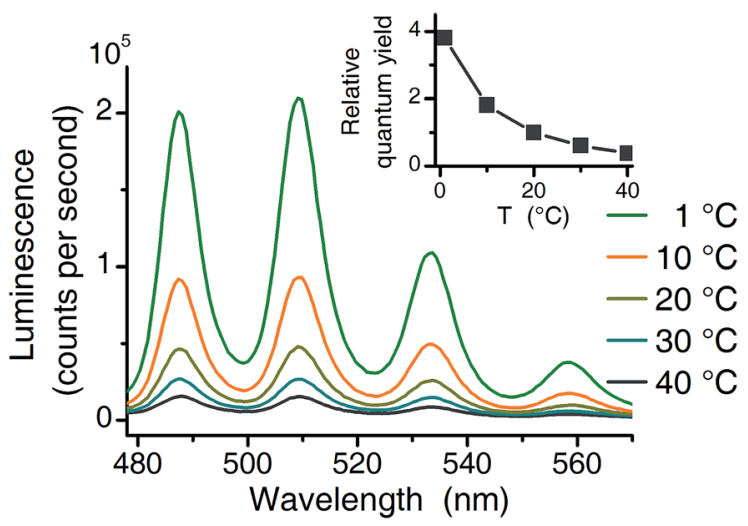

Fig. 2 Temperature effect $\left(1^{\circ} \mathrm{C}\right.$ to $\left.40^{\circ} \mathrm{C}\right)$ on luminescence intensity $\left(10^{-4} \mathrm{MU}(\mathrm{vI}), 10^{-2} \mathrm{M} \mathrm{NaClO}_{4}, \mathrm{pH} 2.5\right.$ excitation at $\left.270 \mathrm{~nm}\right)$. Inset shows the relative quantum yield normalized to $20^{\circ} \mathrm{C}$ value. complexes (colored gray in Fig. 3) could not be reproduced. Significant differences in quantum yields could explain this. ${ }^{\mathbf{4 8}}$ Nevertheless a detailed and consistent uranyl(vi) speciation over a wide $\mathrm{pH}$ range under a fixed uranium concentration is characterized by luminescence spectroscopy for the first time. Peak positions obtained are listed in Table 1 , together with literature values.

The third parameter differs for TRLFS (time) and CW spectroscopy (excitation wavelength). Thus columns of matrices $\mathrm{C}$ represent the luminescence decay for TRLFS and the excitation spectra for CW spectroscopy. As mentioned before a monoexponential restriction was used for PARAFAC with TRLFS data. Therefore extraction of standard deviation for lifetimes is not possible. Lifetimes for both $1{ }^{\circ} \mathrm{C}$ and $25^{\circ} \mathrm{C}$ are given in Table 1 . As expected the lifetimes increase with decreasing 

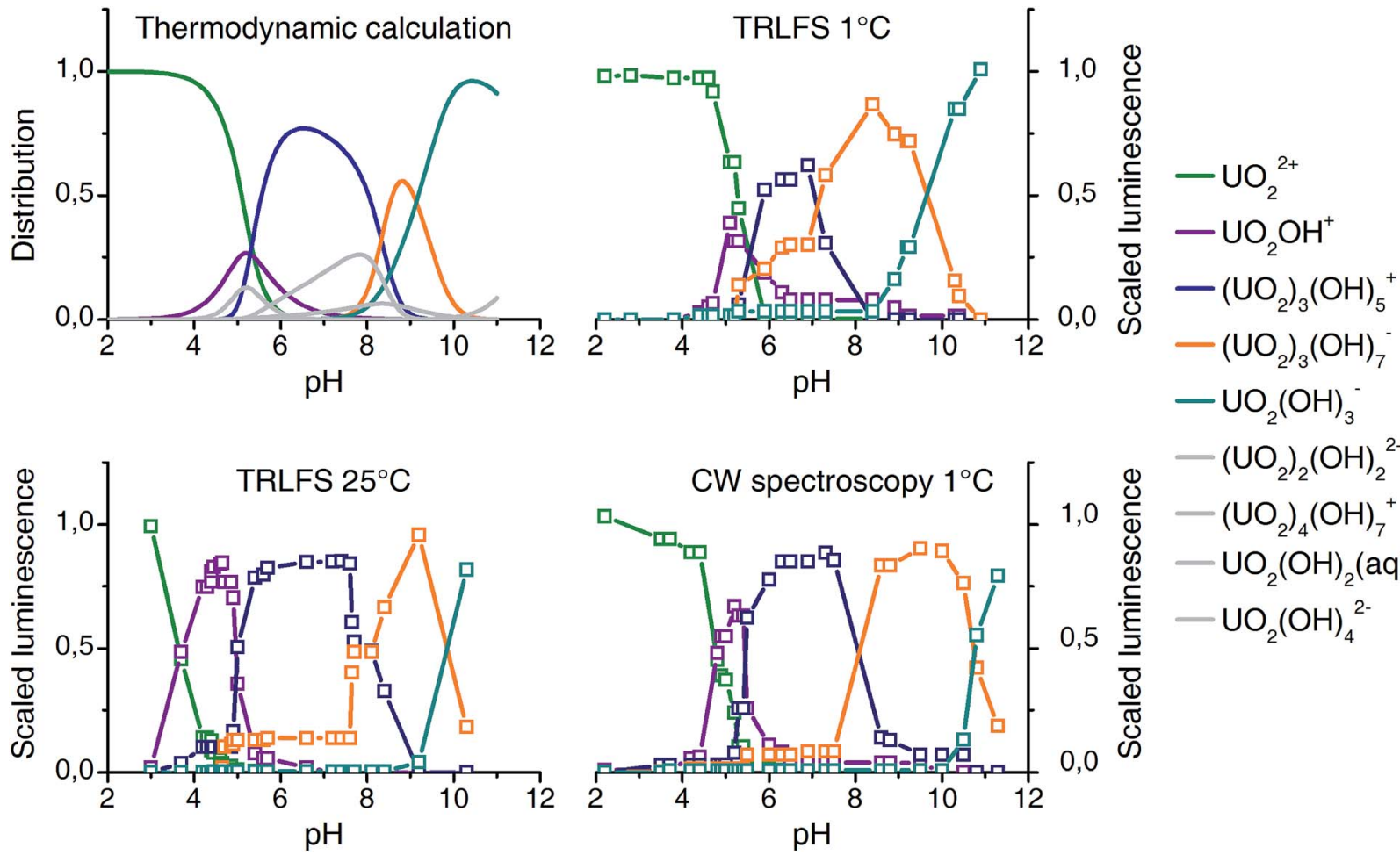

$-\left(\mathrm{UO}_{2}\right)_{2}(\mathrm{OH})_{2}^{2+}$

$-\left(\mathrm{UO}_{2}\right)_{4}(\mathrm{OH})_{7}^{+}$

$-\mathrm{UO}_{2}(\mathrm{OH})_{2}(\mathrm{aq})$

$-\mathrm{UO}_{2}(\mathrm{OH})_{4}^{2-}$

Fig. 3 Comparison of thermodynamic speciation (top left, $25^{\circ} \mathrm{C}$ ) with experimental distribution based on luminescence spectroscopy and PARAFAC deconvolution $\left(10^{-5} \mathrm{M} \mathrm{U}(\mathrm{vl}), 10^{-2} \mathrm{M} \mathrm{NaClO}_{4}\right)$.

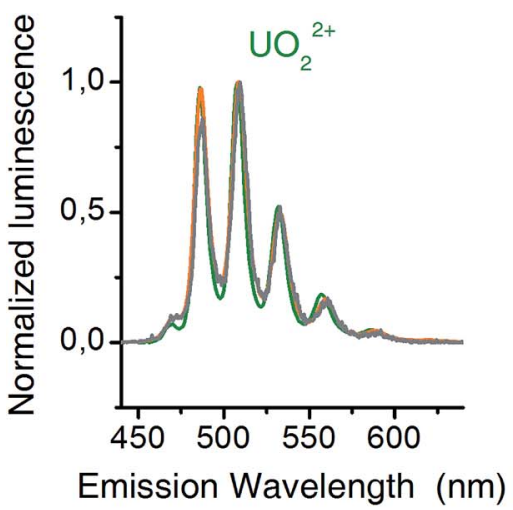

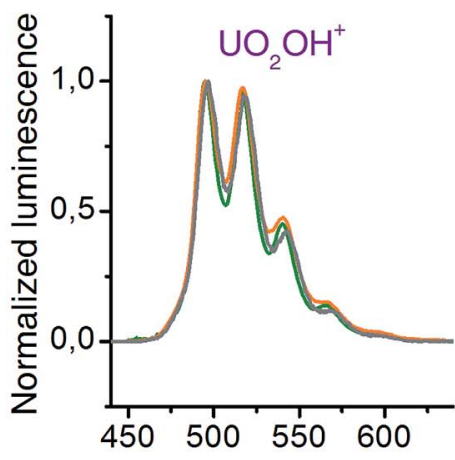

Emission Wavelength (nm)

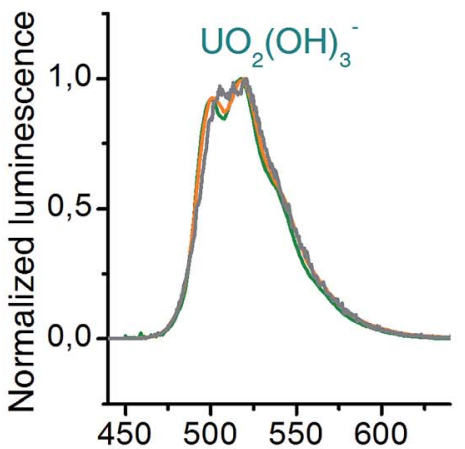

Emission Wavelength $(\mathrm{nm})$
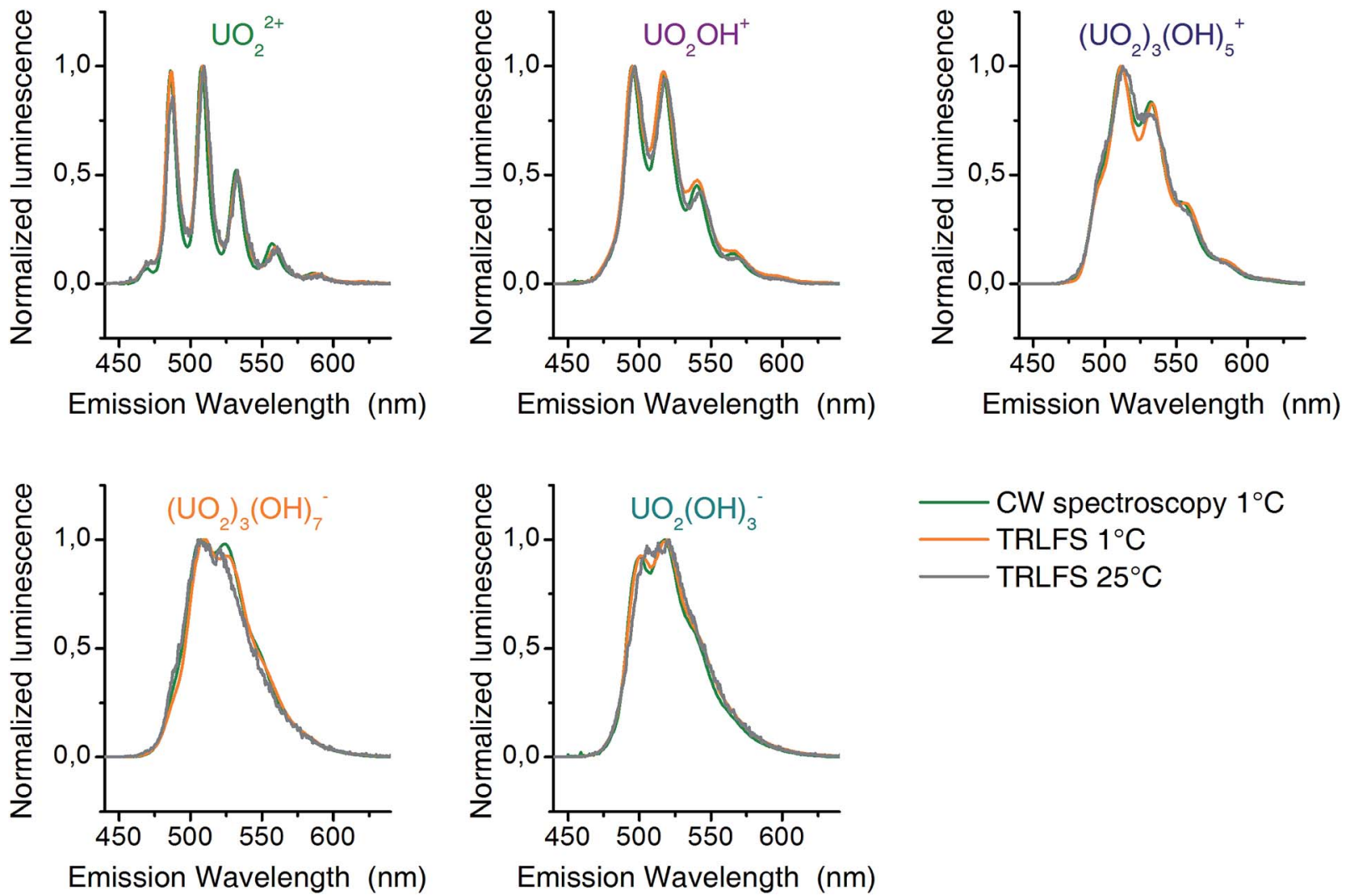

Fig. 4 Luminescence spectra (normalized to maximum amplitude) of detected uranyl(vı) complexes from $\mathrm{CW}$-spectroscopy $\left(1{ }^{\circ} \mathrm{C}-\mathrm{green}\right)$ and TRLFS $\left(1^{\circ} \mathrm{C}\right.$ - orange; $25^{\circ} \mathrm{C}$ - gray). 


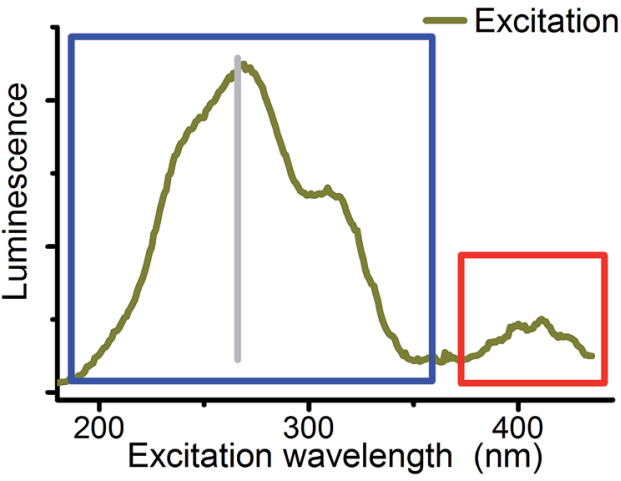

Fig. 5 Excitation spectrum (CW) of $10^{-4} \mathrm{MU}(\mathrm{vI})$ solution at $\mathrm{pH} 2.5$ (emission at $509 \mathrm{~nm}$ ). Red: fingerprint region of uranyl(vI) UV-vis excitation. Blue: field of unspecific excitation (180 to $370 \mathrm{~nm}$ ) used for CW spectroscopy. Gray: fourth harmonic of the Nd:YAG laser (266 nm) used for TRLFS.

temperatures. ${ }^{12}$ Extracted lifetimes are often shorter than those described in the literatures. The difference can be attributed to the differences in ionic strength. ${ }^{49}$ For the complexes $1: 1$ $\left(\mathrm{UO}_{2} \mathrm{OH}^{+}\right)$and $2: 2\left(\left(\mathrm{UO}_{2}\right)_{2}(\mathrm{OH})_{2}{ }^{2+}\right)$ reported lifetimes are contradictory. Longer lifetimes for the $1: 1$ complex $\left(80 \mu \mathrm{s},{ }^{50}\right.$ $39.4 \mu \mathrm{s},{ }^{51} 33.8 \mu \mathrm{s}$ (ref. 52)) compared to those of the $2: 2$ complex $\left(9 \mu \mathrm{s},{ }^{50} 13.4 \mu \mathrm{s},{ }^{51} 11.1 \mu \mathrm{s}\right.$ (ref. 52)) were listed. Kirishima et al. proposed the opposite, $11.3 \mu$ s for the $1: 1$ complex and $17.8 \mu$ s for the $2: 2$ complex. ${ }^{53}$ Because of the proposed similar shape of spectra (Moulin et al. and references therein ${ }^{\mathbf{1 9}}$ ) this problem could not be solved here.

Excitation wavelength was used as the third parameter for the deconvolution of $\mathrm{CW}$ spectroscopic data. Site selective excitation of uranyl(vi) was previously rudimentarily performed in the fingerprint region ${ }^{54,55}$ shown in Fig. 5 (red sector). Theoretical studies were focused on the same region. ${ }^{56,57}$

Although differences in UV absorption below $370 \mathrm{~nm}$ were observed for several uranyl complexes, the common assumption is that this absorption is structureless and not specific. ${ }^{58}$ Therefore systematic studies on site selectivity of uranyl excitation are missing. Wang et al. have shown that the luminescence intensity of solid state uranyl compounds depends on excitation wavelength ${ }^{59}$ and Moulin et al. mentioned in 1998 that studies in this direction are in progress. ${ }^{19}$ The present study is focused on the wavelength range from 180 to $370 \mathrm{~nm}$ (blue sector in Fig. 5) to start systematic investigations on this field.

Differences in excitation spectra can easily be demonstrated with the sample from $\mathrm{pH}$ 5. At this $\mathrm{pH}$ mainly the uranyl(vi) aquo ion and the $1: 1$ complex (see $\mathrm{pH}$ distribution from $\mathrm{CW}$ spectroscopy in Fig. 3) should be present. Selected normalized luminescence spectra from raw data at this $\mathrm{pH}$ are shown in Fig. 6 (right side). These spectra are a superposition of pure spectra of the uranyl(vi) aquo ion and the $1: 1$ complex (see Fig. 4). The ratio of these two complexes differs depending on the excitation wavelength. This is caused by differences in excitation spectra of uranyl(vi) aquo ion and $1: 1$ complex.

Extracted emission spectra as well as $\mathrm{pH}$ distribution pattern from CW spectroscopy are consistent with those from TRLFS measurements. The structure of PARAFAC deconvolution implies that the columns of the third matrix are directly connected to the first two matrices. Therefore the extracted excitation spectra (Fig. 7) belong to the previous defined complexes. Excitation maxima shift from $270 \mathrm{~nm}$ (aquo ion) to $325 \mathrm{~nm} \mathrm{(3:7}$ complex) and thus, a remarkable difference of more than $50 \mathrm{~nm}$ is observed. It should be noted, that the resolution $(5 \mathrm{~nm}$ with $10 \mathrm{~nm}$ bandwidth) of excitation wavelength allows an estimation of maxima with an accuracy of $5 \mathrm{~nm}$.

A summary of all luminescence spectroscopic parameters from this work together with literature values is given in Table 1. The presented data of this study are within variation of previously published results. Different experimental conditions (ionic strength, temperature) as well as equipment setup limit the comparability of luminescence decay times. ${ }^{\mathbf{6 0 , 6 1}}$

In order to examine whether the tentative assignment of the species is realistic, time-dependent DFT (TD-DFT) calculations were performed. TD-DFT was previously applied on actinide complexes to study UV-vis absorption spectra $^{67}$ and X-ray absorption spectra. ${ }^{68,69}$

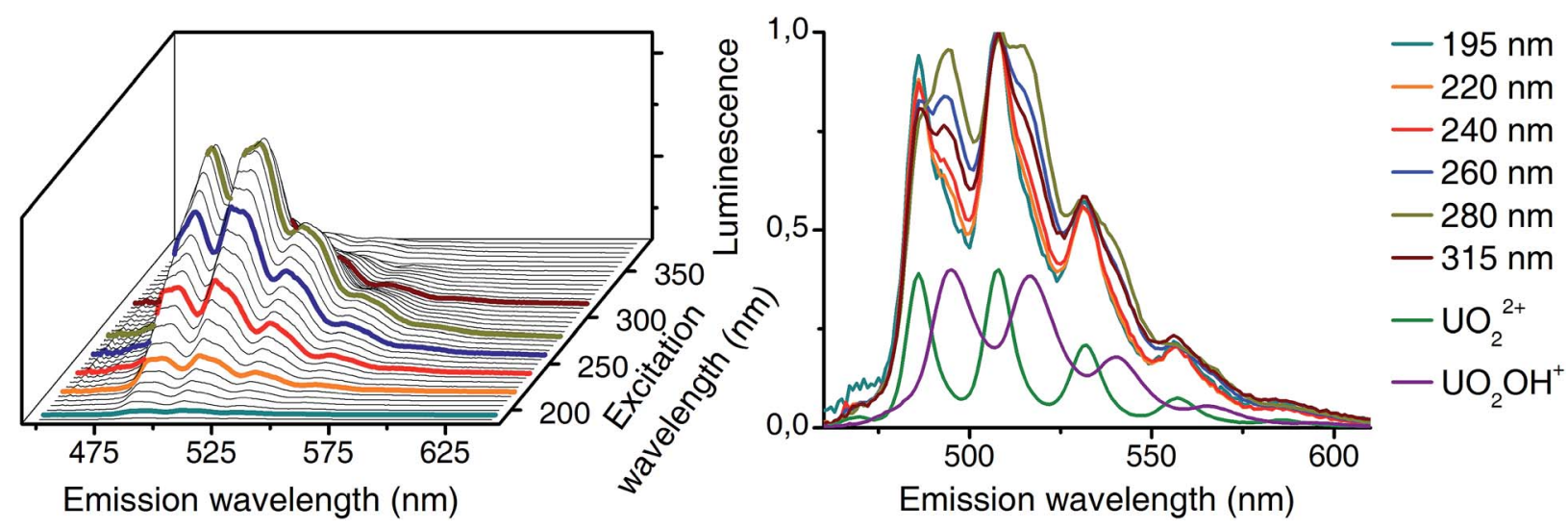

Fig. 6 Left: dependence of luminescence on excitation wavelength ( $\mathrm{CW}$ spectroscopy, $\left.10^{-5} \mathrm{MU}(\mathrm{vl}), 10^{-1} \mathrm{M} \mathrm{NaClO} 4, \mathrm{pH} 5,1^{\circ} \mathrm{C}\right)$. Selected wavelengths are labeled. Right: normalized (maximum at $509 \mathrm{~nm}$ ) emission spectra representing a superposition of uranyl( $\mathrm{vl}$ ) aquo ion ( $\mathrm{green}$ ) and $1: 1$ complex (purple). 


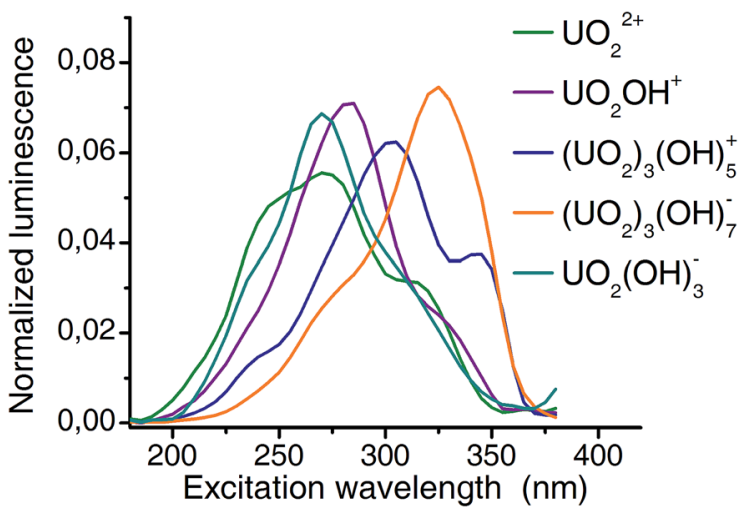

Fig. 7 Extracted excitation spectra for 5 major complexes of uranyl(vi) hydrolysis. A $5 \mathrm{~nm}$ resolution and $10 \mathrm{~nm}$ bandwidth was used for excitation. Excitation maxima shift from $270 \mathrm{~nm}$ (aquo ion) to $325 \mathrm{~nm}$ $\left.\left(\left(\mathrm{UO}_{2}\right)_{3}(\mathrm{OH})_{7}^{-}\right)\right)$

In the calculated spectra of pure water cluster $\left(\left[\left(\mathrm{H}_{2} \mathrm{O}\right)_{11}\right]\right)$ and hydroxo ion cluster $\left(\left[(\mathrm{OH})_{2}\left(\mathrm{H}_{2} \mathrm{O}\right)_{9}\right]^{2-}\right)$ strong absorption were found below $170 \mathrm{~nm}$ and $220 \mathrm{~nm}$, respectively. Therefore calculated uranyl hydroxo absorption features below $220 \mathrm{~nm}$ do not contribute to luminescence and were excluded from the spectra. Hence, the term 'excitation spectra' is used for all calculated absorption spectra to avoid confusions in comparing experiment and calculation.

Large manifold of states between $200 \mathrm{~nm}$ and $300 \mathrm{~nm}$ creates overall broad excitation in the calculated excitation spectra of the uranyl(vi) aquo ion. Among them, there are four major peaks at $272 \mathrm{~nm}$ (excited state \#7), $252 \mathrm{~nm}(\# 16), 232 \mathrm{~nm}(\# 33)$, and $219 \mathrm{~nm}$ (\#39). Peak \#7 occurs via electron transfer from the molecular orbital (MO) 47 to MO 51. The MO 47 consists mainly of oxygen $2 \mathrm{p}$ atomic orbital (AO) of coordinating water molecule, whereas MO 51 consists primarily of uranium $5 \mathrm{f}_{\delta} \mathrm{AO}$. Therefore the excitation \#7 can be described as ligand-to-metal charge transfer (LMCT) state by electron transfer from coordinating water to uranium. Similarly, other excitation states (\#16, $\# 33$, \#39) occur also by water to $\mathrm{U} 5 \mathrm{f}_{\delta} / 5 \mathrm{f}_{\phi}$ charge transfer. In the calculated excitation spectra of the aquo ion there are four major states of similar origin. They are degenerate because of slightly different orientation of water-to-uranium coordination.
Two major features at around $300 \mathrm{~nm}$ and $250 \mathrm{~nm}$ dominate the calculated spectra of the $1: 1\left(\mathrm{UO}_{2} \mathrm{OH}^{+}\right)$species. Both consist of superposition of several excitations. The former (which appears as a shoulder) consists mainly of the excited state \#8 which originates from MO 47 to MO 51 transition. The two MOs consist primarily of $\mathrm{O} 2 \mathrm{p}$ from $\mathrm{OH}^{-}$ligand and $\mathrm{U} 5 \mathrm{f}_{\delta} /$ $5 f_{\phi}$, respectively. Therefore an $\mathrm{OH}^{-}$to $\mathrm{U}$ charge transfer is responsible for this shoulder. The strong excitation at around $250 \mathrm{~nm}$ consists essentially of excited state \#18 (MO 45 to MO 50 transition) which represents ligand water to $\mathrm{U}$ charge transfer. Spectra shape and relative position (compared to uranyl(vi) aquo ion) show, that the experimental obtained lifetime around $8 \mu \mathrm{s}$ is connected to the $1: 1$ but not the $2: 2$ complex (see ESI $\dagger$ ).

In the calculated spectra of the $3: 5$ species there are three main excitation features at around $310 \mathrm{~nm}, 280 \mathrm{~nm}$, and 240 $\mathrm{nm}$. The first peak can be assigned to excitations from $\mathrm{O}_{\mathrm{OH}} \mathrm{MO}$ to U MO. Both additional spectral features result from an analogous ligand-to-metal charge transfer from $\mathrm{O}_{\text {central }}$ and $\mathrm{O}_{\mathrm{H}_{2} \mathrm{O}}$, respectively.

The presence and orientation of second shell waters significantly affect the calculated excitation spectra of negatively charged uranyl(vi) species. However, the orientation of such water is not at all obvious and requires input from molecular dynamics simulations. ${ }^{70-72}$ Therefore exclusively spectra of positively charged species are compared in Fig. 8 (complexes $1: 3$ and $3: 7$ not shown).

Previously TD-DFT was used to study the photoexcitation of bare $\mathrm{UO}_{2}{ }^{2+}$ ion $^{73}$ as well as its coordination complexes. ${ }^{74-76}$ Generally the performance of TD-DFT method is rather poor in predicting the excitation energies of uranyl(vi) especially of higher excited states. This is presumably due to the neglect of double excitations in the scheme of single-determinant method. In the present investigation, in which the higher excited states are concerned, the TD-DFT method has an intrinsic limitation. Although absolute energy has a discrepancy in the order of several thousands of wavenumbers experimental excitation features are overall well reproduced by the TD-DFT calculations (Fig. 8). Since all excitation bands shown here are the LMCT states and do not involve the $\mathrm{U}-\mathrm{O}_{\mathrm{ax}}$ bond, there is minimal effect of neglecting double excitations. Summarized,

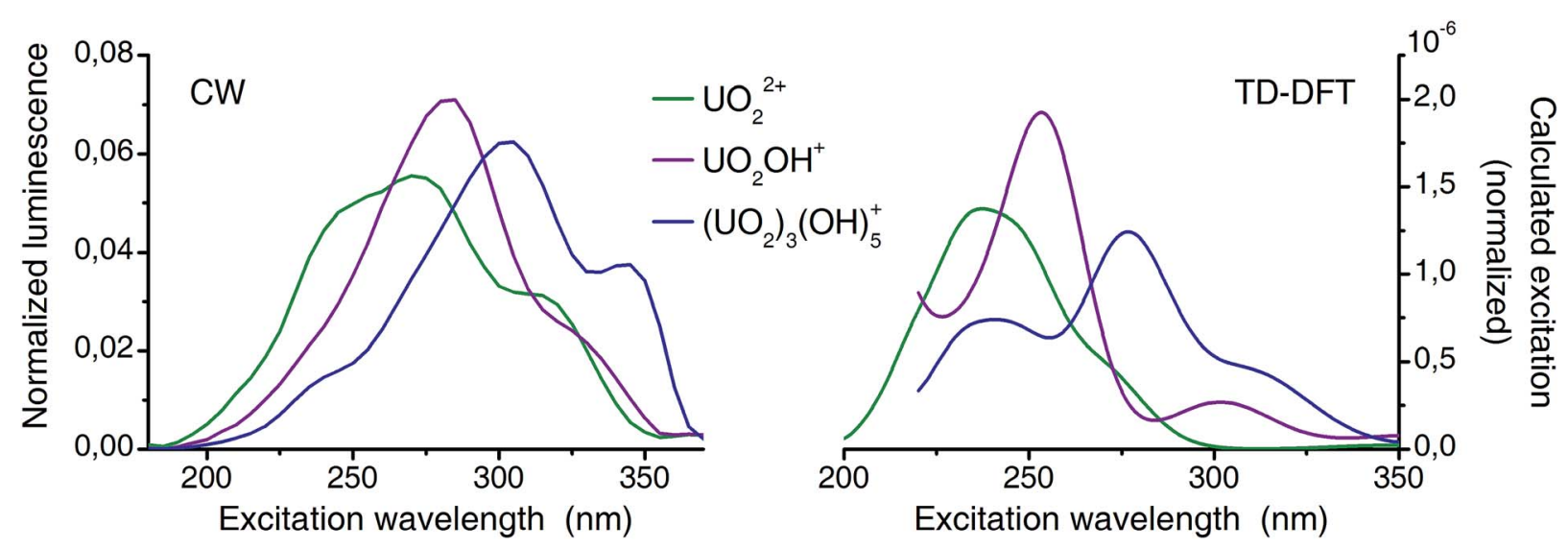

Fig. 8 Comparison of deconvoluted (from CW-spectroscopy) and calculated (TD-DFT) excitation spectra (normalized to area). 
the calculated spectra reproduce the features of the corresponding experimental spectra very well and confirmed that the experimental excitation spectra truly belong to the assigned species (aquo, $1: 1$, and $3: 5$ ).

\section{Conclusions}

In this study a powerful and advanced combination of experimental (TRLFS and CW-spectroscopy) and theoretical (PARAFAC and TD-DFT) methods was proposed for the speciation of luminescent metals. It has been demonstrated to be successful for uranyl(vI) hydrolysis without contradictions to the literature. A consistent spectroscopic detection as well as identification of species distribution of major hydrolysis species (uranyl(VI) aquo ion, $1: 1,3: 5,3: 7,1: 3$ ) within one experimental setup (fixed uranyl(vI) concentration $[\mathrm{U}]=10^{-5} \mathrm{M}, \mathrm{pH} 2$ to 11$)$ was achieved for the first time. Spectra shape and lifetimes were found to be well comparable with those in the literature.

Deconvolution of strong overlapping excitation spectra is not straightforward. As before, PARAFAC has demonstrated its validity and robustness. Therefore the deconvolution of heavy metal luminescence data, based on differences in excitation, can be applied at room temperature. Individual excitation spectra of detected uranyl(vi) hydrolysis species were extracted for a UV range from $180 \mathrm{~nm}$ to $370 \mathrm{~nm}$. This impressively demonstrates for the first time that excitation in this region is highly sensitive and specific. According to the TD-DFT calculations, excitation in this spectral range is due to ligand-to-metal charge transfer (LMCT) and the spectra features are ligand specific (water, hydroxo, oxo). Therefore even the shape of the uranyl(vi) excitation spectra is indicative of complex stoichiometry.

Luminescence decay is an excellent parameter to discriminate between several uranyl(vi) complexes. However, a correlation with structure is difficult and reported lifetimes are often inconsistent. ${ }^{60}$ Moreover the choice of the laser wavelength for TRLFS measurements can directly influence the results. A better discrimination of several uranyl(vi) compounds with accessible structural information might be achieved by the 'site sensitive excitation' here proposed. Therefore further elucidation of the thermodynamics of uranyl(vi) polynuclear species becomes possible.

This combination of experimental and theoretical methods can be applied for better understanding the speciation of luminescent metals in general. In addition to actinides (e.g. Np, $\mathrm{U}, \mathrm{Am}, \mathrm{Cm}$ ) an application area is coordination chemistry of rare earth elements (e.g. Ce, $\mathrm{Nd}, \mathrm{Eu}, \mathrm{Tb}$ ) which are of strategic importance for high-technology products world-wide.

\section{Acknowledgements}

The authors thank Frank Bok for the EQ3/6 calculations. All quantum-chemical calculations were performed using PC-Farm Atlas at the Center for Information Services and High Performance Computing (ZIH) at the Technische Universität Dresden, Germany, using the library program Gaussian 09.

\section{References}

1 R. Xie, W. Johnson, S. Spayd, G. S. Hall and B. Buckley, Anal. Chim. Acta, 2006, 578, 186-194.

2 J. Bayona, Trends Anal. Chem., 2000, 19, 107-112.

3 H. Sodaye, S. Nisan, C. Poletiko, S. Prabhakar and P. Tewari, Desalination, 2009, 235, 9-32.

4 W. Li, J. Zhao, C. Li, S. Kiser and R. Jack Cornett, Anal. Chim. Acta, 2006, 575, 274-280.

5 A. C. Fournier, K. L. Shafran and C. C. Perry, Anal. Chim. Acta, 2008, 607, 61-73.

6 P. L. Zanonato, D. B. Plinio and I. Grenthe, Dalton Trans., 2014, 43, 2378-2383.

7 C. Walther, M. Fuss and S. Buchner, Radiochim. Acta, 2008, 96, 411-426.

8 H. Zhao, H. Liu and J. Qu, J. Colloid Interface Sci., 2009, 330, 105-112.

9 R. Guillaumont, T. Fanghänel, V. Neck, J. Fuger, D. A. Palmer, I. Grenthe and M. H. Rand, Update on the chemical thermodynamics of uranium, neptunium, plutonium, americium and technetium, Elsevier Amsterdam, 2003.

10 K. Müller, V. Brendler and H. Foerstendorf, Inorg. Chem., 2008, 47, 10127-10134.

11 P. L. Brown, Radiochim. Acta, 2002, 90, 589-593.

12 P. Zanonato, P. Di Bernardo, A. Bismondo, G. Liu, X. Chen and L. Rao, J. Am. Chem. Soc., 2004, 126, 5515-5522.

13 L. Rao, Chem. Soc. Rev., 2007, 36, 881-892.

14 K. Müller, H. Foerstendorf, S. Tsushima, V. Brendler and G. Bernhard, J. Phys. Chem. A, 2009, 113, 6626-6632.

15 H. Moll, A. Rossberg, R. Steudtner, B. Drobot, K. Müller and S. Tsushima, Inorg. Chem., 2014, 53, 1585-1593.

16 D. L. Clark, S. D. Conradson, R. J. Donohoe, D. W. Keogh, D. E. Morris, P. D. Palmer, R. D. Rogers and C. D. Tait, Inorg. Chem., 1999, 38, 1456-1466.

17 F. Quilès, C. Nguyen-Trung, C. Carteret and B. Humbert, Inorg. Chem., 2011, 50, 2811-2823.

18 Z. Szabó and I. Grenthe, Inorg. Chem., 2010, 49, 4928-4933.

19 C. Moulin, I. Laszak, V. Moulin and C. Tondre, Appl. Spectrosc., 1998, 52, 528-535.

20 Z. Wang, J. M. Zachara, W. Yantasee, P. L. Gassman, C. Liu and A. G. Joly, Environ. Sci. Technol., 2004, 38, 5591-5597.

21 J. Tits, G. Geipel, N. Macé, M. Eilzer and E. Wieland, J. Colloid Interface Sci., 2011, 359, 248-256.

22 D. Beltrami, F. Mercier-Bion, G. Cote, H. Mokhtari, B. Courtaud, E. Simoni and A. Chagnes, J. Mol. Liq., 2014, 190, 42-49.

23 M. Marques Fernandes, M. Schmidt, T. Stumpf, C. Walther, D. Bosbach, R. Klenze and T. Fanghänel, J. Colloid Interface Sci., 2008, 321, 323-331.

24 K. Holliday, C. Babelot, C. Walther, S. Neumeier, D. Bosbach and T. Stumpf, Radiochim. Acta, 2012, 100, 189-195.

25 J. Carroll and J.-J. Chang, Psychometrika, 1970, 35, 283-319.

26 R. A. Harshman, UCLA Working Papers in Phonetics, 1970, 16, 1-84.

27 C. A. Andersson and R. Bro, Chemom. Intell. Lab. Syst., 2000, 52, 1-4. 
28 N. P. Sanchez, A. T. Skeriotis and C. M. Miller, Water Res., 2013, 47, 1679-1690.

29 J. Schott, et al., Dalton Trans., 2014, 43, 11516-11528.

30 T. Saito, H. Sao, K. Ishida, N. Aoyagi, T. Kimura, S. Nagasaki and S. Tanaka, Environ. Sci. Technol., 2010, 44, 5055-5060.

31 R. Bro, Chemom. Intell. Lab. Syst., 1997, 38, 149-171.

32 R. Bro and H. A. L. Kiers, J. Chemom., 2003, 17, 274-286.

33 R. Bro and A. K. Smilde, J. Chemom., 2003, 17, 16-33.

34 R. Bro, The N-way on-line course on PARAFAC and PLS, http:// www.models.life.ku.dk/courses, 1998-2002.

35 M. J. Frisch, et al., Gaussian 09 Revision A.2, Gaussian Inc., Wallingford CT, 2009.

36 V. Barone and M. Cossi, J. Phys. Chem. A, 1998, 102, 19952001.

37 M. Cossi, N. Rega, G. Scalmani and V. Barone, J. Comput. Chem., 2003, 24, 669-681.

38 A. D. Becke, J. Chem. Phys., 1993, 98, 5648-5652.

39 C. Lee, W. Yang and R. G. Parr, Phys. Rev. B: Condens. Matter Mater. Phys., 1988, 37, 785.

40 M. E. Casida, C. Jamorski, K. C. Casida and D. R. Salahub, J. Chem. Phys., 1998, 108, 4439-4449.

41 R. E. Stratmann, G. E. Scuseria and M. J. Frisch, J. Chem. Phys., 1998, 109, 8218-8224.

42 W. Küchle, M. Dolg, H. Stoll and H. Preuss, J. Chem. Phys., 1994, 100, 7535-7542.

43 S. Tsushima, Dalton Trans., 2011, 40, 6732-6737.

44 S. Tsushima, Inorg. Chem., 2012, 51, 1434-1439.

45 R. Krishnan, J. Binkley, R. Seeger and J. Pople, J. Chem. Phys., 1980, 72, 650-654.

46 R. Steudtner, T. Arnold, G. Geipel and G. Bernhard, J. Radioanal. Nucl. Chem., 2010, 284, 421-429.

47 T. J. Wolery, EQ3/6: a software package for geochemical modeling of aqueous systems: package overview and installation guide (version 7.0), Lawrence Livermore National Laboratory, Livermore, CA, 1992.

48 G. Meinrath, S. Lis, Z. Stryla and C. Noubactep, J. Alloys Compd., 2000, 300-301, 107-112.

49 M. Moriyasu, Y. Yokoyama and S. Ikeda, J. Inorg. Nucl. Chem., 1977, 39, 2211-2214.

50 C. Moulin, P. Decambox, V. Moulin and J. G. Decaillon, Anal. Chem., 1995, 67, 348-353.

51 V. Eliet, I. Grenthe and G. Bidoglio, Appl. Spectrosc., 2000, 54, 99-105.
52 T. Kimura, R. Nagaishi, M. Arisaka, T. Ozaki and Z. Yoshida, Radiochim. Acta, 2002, 90, 715-720.

53 A. Kirishima, T. Kimura, O. Tochiyama and Z. Yoshida, J. Alloys Compd., 2004, 374, 277-282.

54 C. D. Flint, P. A. Tanner, R. Reisfeld and H. Tzehoval, Chem. Phys. Lett., 1983, 102, 249-253.

55 K. Murata and M. Morita, J. Lumin., 1984, 29, 381-387.

56 G. Liu and M. Jensen, Chem. Phys. Lett., 2010, 499, 178-181.

57 G. Liu, L. Rao and G. Tian, Phys. Chem. Chem. Phys., 2013, 15, 17487-17495.

58 G. Meinrath, J. Radioanal. Nucl. Chem., 1997, 224, 119-126.

59 G. Wang, Y. Su and D. L. Monts, J. Phys. Chem. A, 2008, 112, 10502-10508.

60 I. Billard, et al., Appl. Spectrosc., 2003, 57, 1027-1038.

61 G. Budylin, E. Shirshin, V. Fadeev, V. Petrov and S. Kalmykov, Opt. Express, 2013, 21, 20517-20528.

62 V. Eliet, G. Bidoglio, N. Omenetto, L. Parma and I. Grenthe, J. Chem. Soc., Faraday Trans., 1995, 91, 2275-2285.

63 Y. Kato, G. Meinrath, T. Kimura and Z. Yoshida, Radiochim. Acta, 1994, 64, 107-112.

64 G. Bernhard, G. Geipel, V. Brendler and H. Nitsche, Radiochim. Acta, 1996, 74, 87-92.

65 G. Meinrath, Y. Kato and Z. Yoshida, J. Radioanal. Nucl. Chem., 1993, 174, 299-314.

66 G. Geipel, A. Brachmann, V. Brendler, G. Bernhard and H. Nitsche, Radiochim. Acta, 1996, 75, 199-204.

67 J. Wiebke, A. Moritz, M. Glorius, H. Moll, G. Bernhard and M. Dolg, Inorg. Chem., 2008, 47, 3150-3157.

68 S. A. Kozimor, et al., Inorg. Chem., 2008, 47, 5365-5371.

69 S. A. Kozimor, et al., J. Am. Chem. Soc., 2009, 131, 1212512136.

70 M. Bühl, R. Diss and G. Wipff, J. Am. Chem. Soc., 2005, 127, 13506-13507.

71 M. Bühl, G. Schreckenbach, N. Sieffert and G. Wipff, Inorg. Chem., 2009, 48, 9977-9979.

72 M. Bühl and G. Schreckenbach, Inorg. Chem., 2010, 49, 38213827.

73 F. Réal, V. Vallet, C. Marian and U. Wahlgren, J. Chem. Phys., 2007, 127, 214302.

74 J. Wiebke, A. Weigand, D. Weissmann, M. Glorius, H. Moll, G. Bernhard and M. Dolg, Inorg. Chem., 2010, 49, 6428-6435.

75 S. Tsushima, Inorg. Chem., 2009, 48, 4856-4862.

76 S. Tsushima, C. Goetz and K. Fahmy, Chem.-Eur. J., 2010, 16, 8029-8033. 